Supporting Information

for

\title{
JP-8 Desulfurization by CuNa-Y zeolite at elevated temperatures has two distinct stages: Chemisorption followed by surface reactions
}

\author{
Priscilla Dias da Silva ${ }^{1}$, Michael S. Wong ${ }^{1,2,3,4,{ }^{*}}$, Kyriacos Zygourakis ${ }^{1,5, *}$ \\ ${ }^{1}$ Department of Chemical and Biomolecular Engineering, ${ }^{2}$ Department of Chemistry, \\ ${ }^{3}$ Department of Civil and Environmental Engineering, ${ }^{4}$ Department of Materials Science and \\ NanoEngineering, ${ }^{5}$ Department of Bioengineering, \\ Rice University, Houston, TX.
}

*Corresponding authors, Email: kyzy@ rice.edu, mswong@rice.edu 


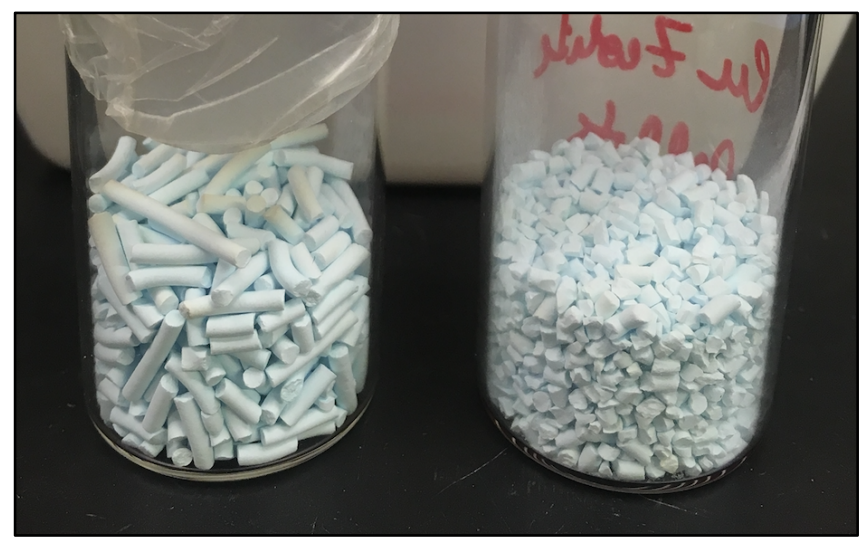

Figure S1. CuNa-Y zeolite pellets as received from Riogen Inc. (left) and crushed (right). The dimensions of the extrudates were initially $1.6 \mathrm{~mm}$ in diameter and $2-10 \mathrm{~mm}$ in length. The extrudates were crushed using an automated mortar and pestle, resulting in pellets of $1.6 \mathrm{~mm}$ in diameter and 2-4 mm in length. Smaller particles and dust were removed using a mesh No. 18 (1 $\mathrm{mm})$. 


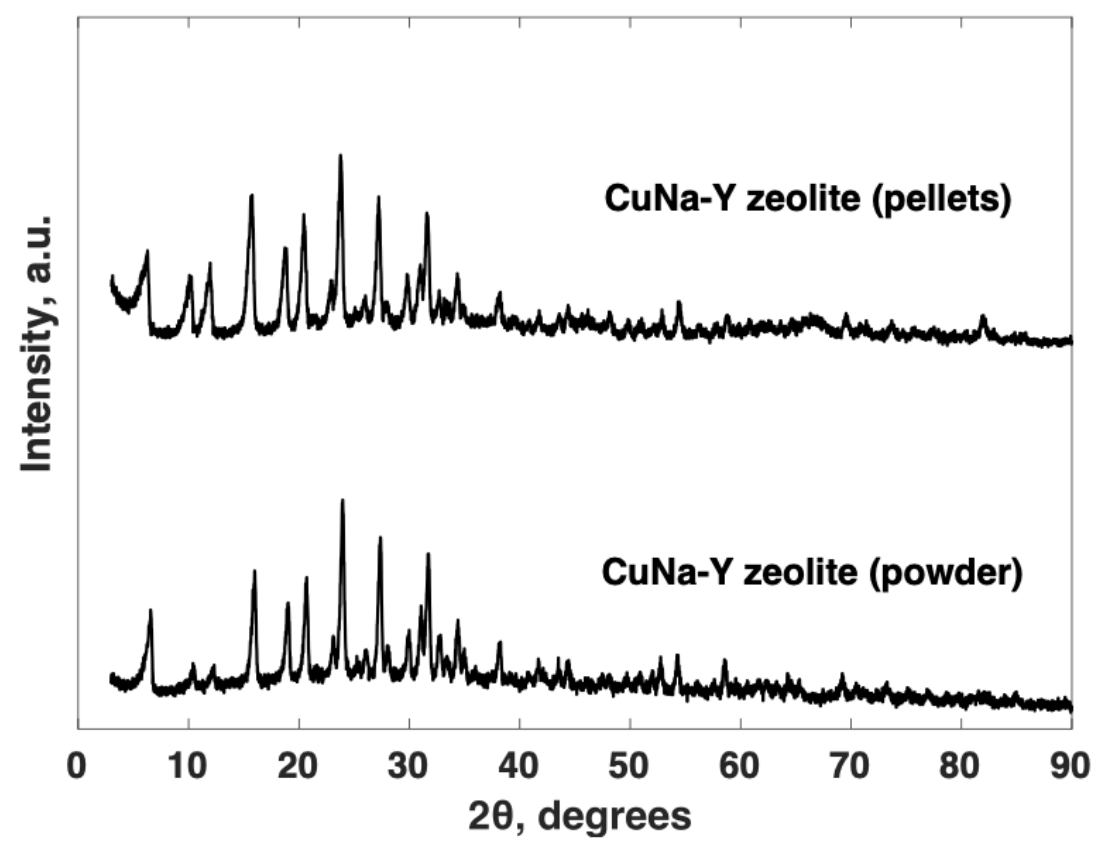

Figure S2. XRD diffraction patterns of CuNa-Y zeolite powder, for reference, (bottom scan), and CuNa-Y zeolite pellets (top scan). The zeolites retained their original crystalline structure after palletization. Powder X-ray diffraction (XRD) patterns were collected on a Rigaku D/Max Ultima II diffractometer $(40 \mathrm{kV}, 40 \mathrm{~mA})$ using $\mathrm{Cu}-\mathrm{K} \alpha$ radiation. All samples were activated under $\mathrm{He}$ at $450{ }^{\circ} \mathrm{C}$ for 3 hours. 

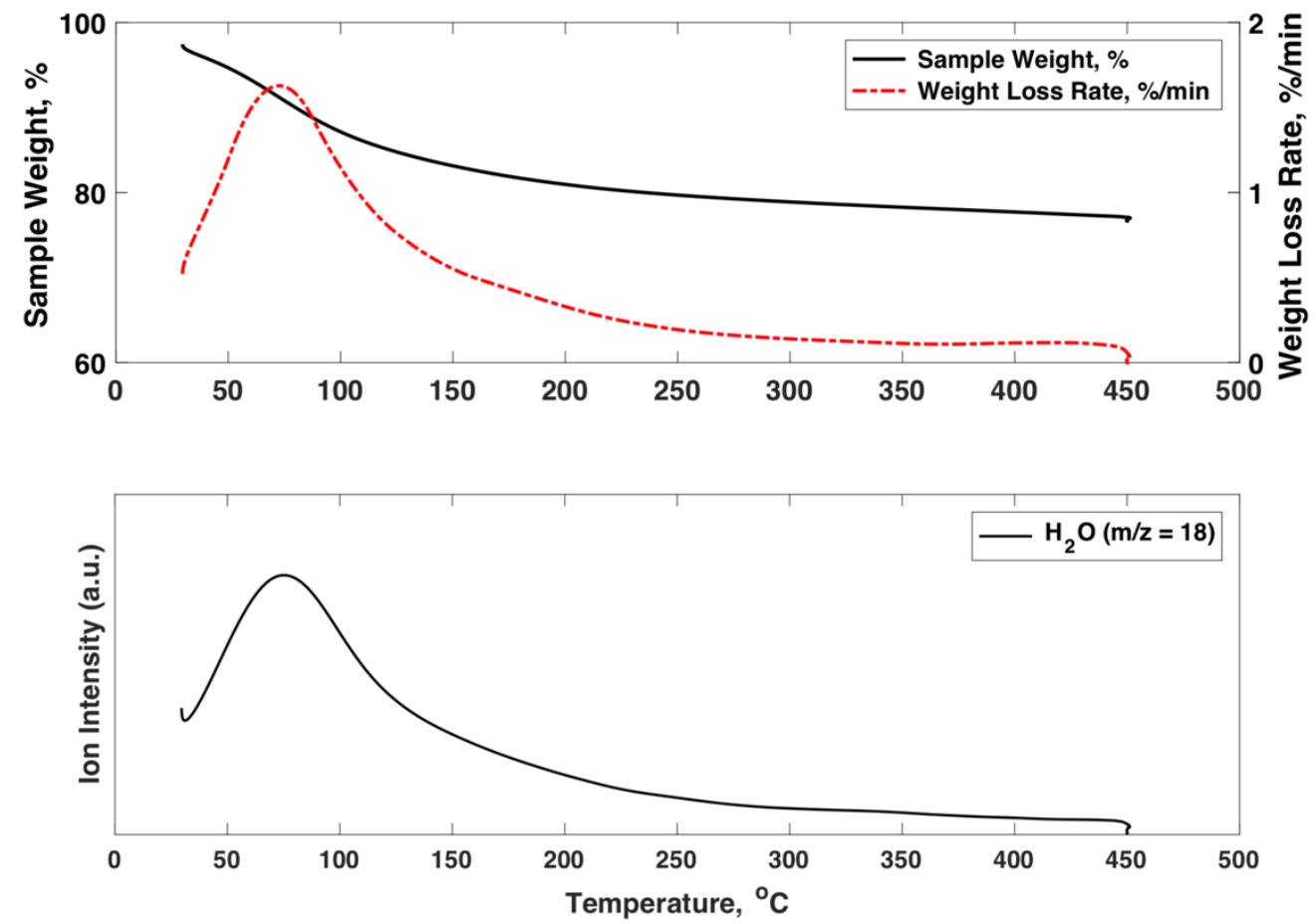

Figure S3. Thermogravimetric analysis coupled with mass spectrometry (TGA-MS) was used to simulate the $\mathrm{CuNa}-\mathrm{Y}$ zeolite pellets activation procedure to determine the weight of adsorbent during desulfurization. The activation temperature program, as well as the TGA program, consist of heating the $\mathrm{CuNa}-\mathrm{Y}$ zeolite pellets to $450{ }^{\circ} \mathrm{C}$ at $10{ }^{\circ} \mathrm{C} / \mathrm{min}$ rate and hold the temperature for 3 hours under inert atmosphere. The weight loss profile (top) and the ion intensities of water (bottom) were obtained by thermogravimetry coupled with a mass spectrometer (TG-MS) under helium gas. The ion intensity of the primary fragment of water $(\mathrm{m} / \mathrm{z}=18)$ was monitored as a function of the TPD temperature. The detected ion intensity was processed to correct the baseline and smooth the signal. The overall weight loss during activation of the adsorbents was determined to be $23.3 \%$ of its initial weight, resulting in $78.6 \mathrm{~g}$ of adsorbent in the reactor after activation. 


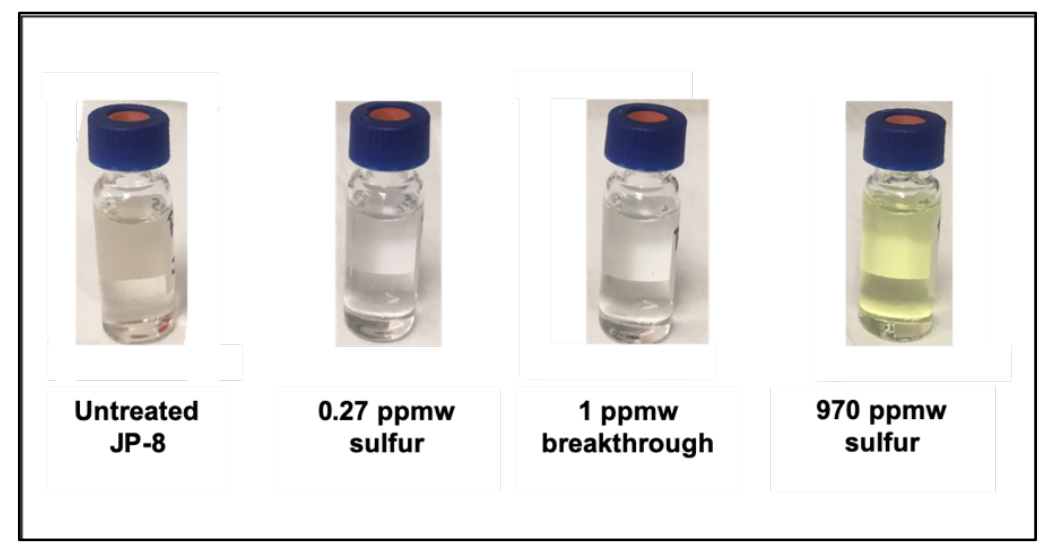

Figure S4. Color of untreated JP-8 (left) and JP-8 treated with $\mathrm{Cu}-\mathrm{Y}$ zeolite pellets at $180{ }^{\circ} \mathrm{C}, 200$ psig and $0.2 \mathrm{~mL} / \mathrm{min}$ at different outlet sulfur concentrations (different times). JP-8 initially contained 2,230 ppmw sulfur. The color of the delivered fuel changed from transparent before breakthrough to a bright yellow after breakthrough. 


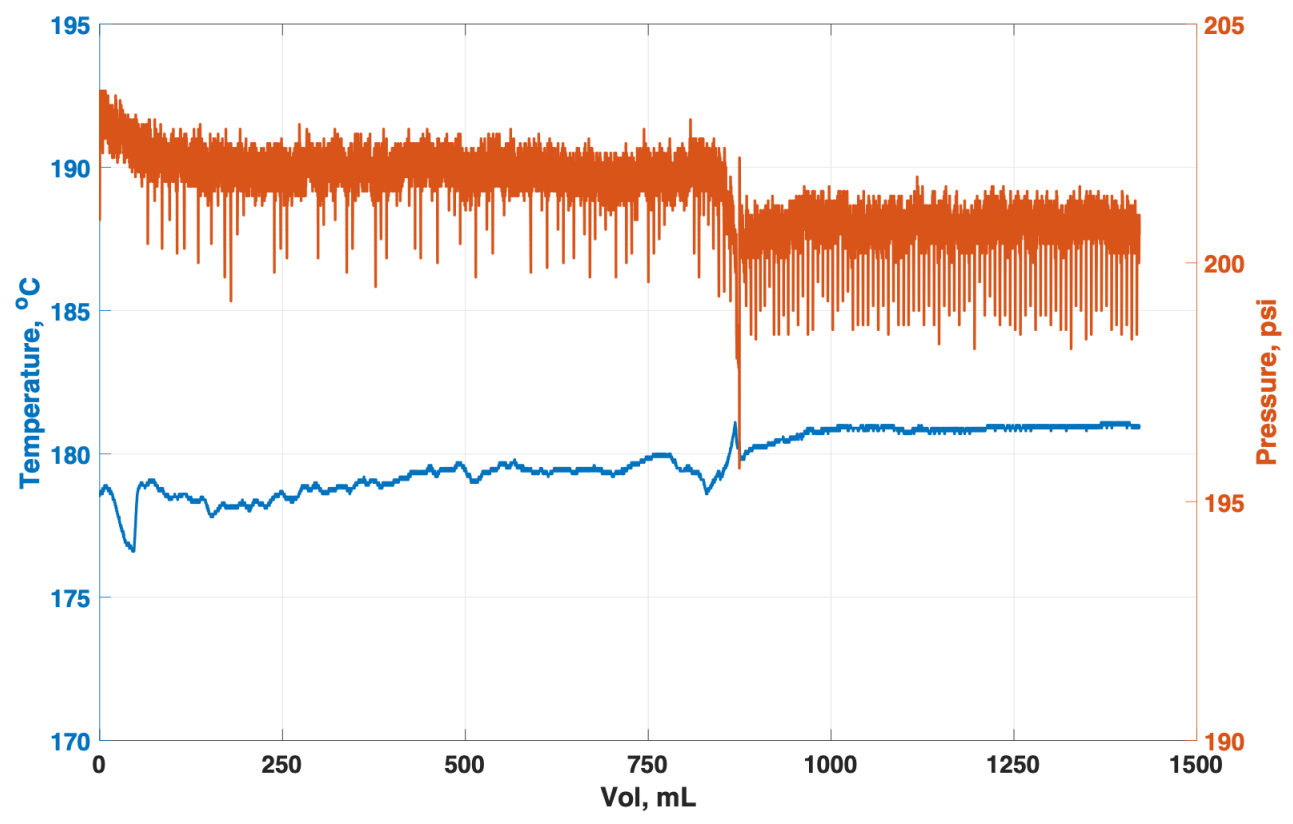

Figure S5. Internal temperature and pressure profiles of the reactor tube for the desulfurization of JP-8 using $\mathrm{Cu}-\mathrm{Y}$ zeolite at $180{ }^{\circ} \mathrm{C}, 200 \mathrm{psig}$ and $0.2 \mathrm{~mL} / \mathrm{min}$ flow rate. The initial sulfur concentration in JP-8 was 2,230 ppmw. The internal temperature of the reactor was kept at $180{ }^{\circ} \mathrm{C}$ $\pm 3{ }^{\circ} \mathrm{C}$ and the pressure was maintained at $200 \mathrm{psig} \pm 3 \mathrm{psig}$. At around $875 \mathrm{~mL}$ volume delivered, a small perturbation in temperature and pressure occurred. This may indicate the moment when surface reactions were triggered. Similar cumulative volume delivered values correspond to the initial detection of hydrogen sulfide. One should note that big variations in temperature were not expected with these surface reactions since the sulfur compounds are present in fuels at very low concentrations and since the overall hydrocarbon matrix in the JP-8 was preserved (Figure 4A). 


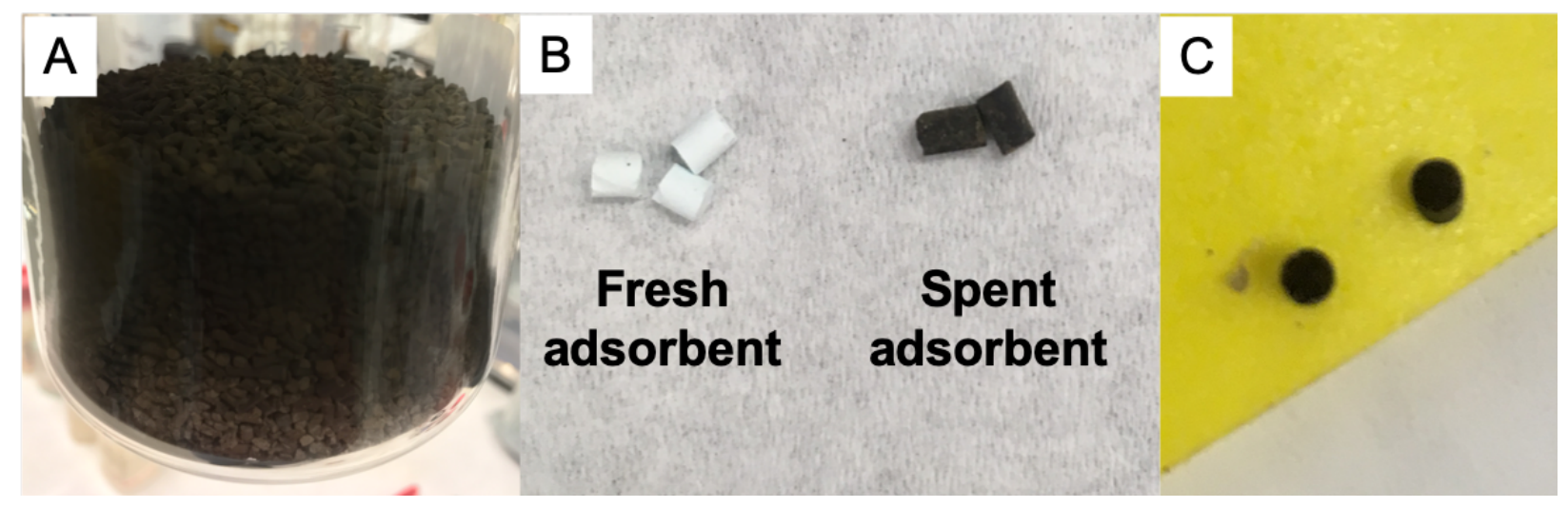

Figure S6. Images of fresh and spent $\mathrm{Cu}-\mathrm{Na}-\mathrm{Y}$ zeolite pellets.

(A) Spent CuNa-Y zeolite pellets after desulfurization at $180{ }^{\circ} \mathrm{C}, 200 \mathrm{psi}$ and $0.2 \mathrm{~mL} / \mathrm{min}$. The dimensions of the extrudates were $1.6 \mathrm{~mm}$ in diameter and 2-4 $\mathrm{mm}$ in length.

(B) Color difference between fresh CuNa-Y zeolite (left) and spent adsorbent (right).

(C) Spent CuNa-Y zeolite broken into two parts. The darker color acquired by the particles upon desulfurization was uniform throughout the interior of the particle. Desulfurization at higher flow rates $(1$ or $5 \mathrm{~mL} / \mathrm{min}$ ) resulted in lighter spent adsorbent particles, when compared to $0.2 \mathrm{~mL} / \mathrm{min}$, due to the incomplete utilization of the adsorbent bed (Figure 7). 



Figure S7. (A) UV-Vis spectra of untreated JP-8 and JP-8 treated with CuNa-Y zeolite pellets at $180{ }^{\circ} \mathrm{C}, 200 \mathrm{psi}$ and $0.2 \mathrm{~mL} / \mathrm{min}$ collected at different times. As the treatment continued after breakthrough, a red shift in the absorbance spectra was observed. JP-8 initially contained 2,230 ppmw sulfur. The diluted sample $(\mathrm{t}=3.32$ days, diluted 1:9) was diluted in $n$-dodecane with a 1:9 ratio by volume.

(B) UV-Vis spectra of pure aromatic compounds retrieved from NIST Webbook. Figure S7B shows that aromatic compounds with higher number of benzene rings generate UV-Vis spectra with absorbance at higher wavelength values.

Figure S7(A) shows that untreated JP-8 presented very little absorbance in the visible light range. The subtle color in untreated JP-8 is commonly attributed to oxidized aromatic compounds, which can be formed during fuel storage due to the presence of headspace oxygen or oxygen dissolved in the fuel [1]. The UV-Vis spectra of JP-8 after desulfurization treatment before breakthrough $($ time $=1.22$ days, sulfur concentration $=0.04 \mathrm{ppmw}$ ) shows no absorbance near the visible range. This could be attributed to the removal of aromatic compounds in fuel during desulfurization with $\mathrm{Cu}-\mathrm{Y}$ zeolite, as this competitive adsorption behavior had been previously reported, although less significant at elevated temperature [2], [3]. At 1 ppmw sulfur breakthrough 
(time $=2.37$ days), absorbance in the visible spectra is observed. Moreover, significantly after breakthrough (time $=3.32$ days), the absorbance had shifted to higher wavelengths and the concentration of the responsible compounds had increased. As seen in Figure S7(B), while typical aromatic compounds in JP-8 such as toluene and butyl-benzene show absorbance until around 300 $\mathrm{nm}$, aromatic compounds containing more aromatic rings present UV-Vis absorbance at higher wavelength ranges. Although UV-Vis cannot be used for speciation of JP-8, the red shift in the UV-Vis pattern of the treated fuel is compatible with the expected spectra of samples that produced aromatic compounds containing several benzene rings during the surface reactions stage of desulfurization. 


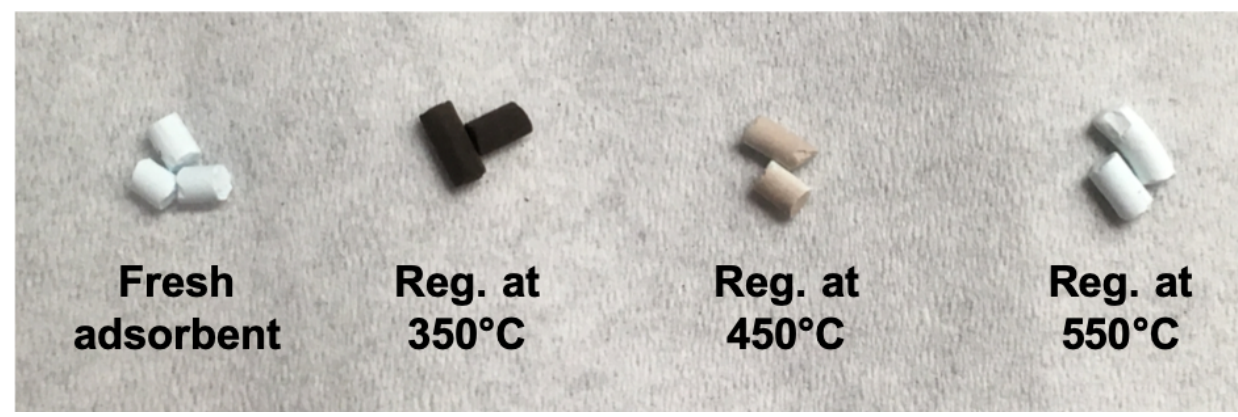

Figure S8. Color of fresh CuNa-Y pellet adsorbent (left) and regenerated samples at different regeneration temperatures. The regeneration program consisted of heating the spent $\mathrm{CuNa}-\mathrm{Y}$ zeolite pellets to 350,450 or $550{ }^{\circ} \mathrm{C}$ at $10{ }^{\circ} \mathrm{C} / \mathrm{min}$ heating rate and holding the temperature for 3 hours under oxidative atmosphere (air). At regeneration temperatures below $550{ }^{\circ} \mathrm{C}$, the regenerated adsorbent pellets did not become pale blue (color of fresh adsorbent). This indicates that samples regenerated at temperatures below $550{ }^{\circ} \mathrm{C}$ still retained carbonaceous deposits formed during desulfurization. The dimensions of the extrudates were $1.6 \mathrm{~mm}$ in diameter and $2-4 \mathrm{~mm}$ in length. 


\section{References}

[1] DeWitt, M.J.; West, Z.; Zabarnick, S.; Shafer, L.; Striebich, R.; Higgins, A.; Edwards, T. Effect of Aromatics on the Thermal-Oxidative Stability of Synthetic Paraffinic Kerosene. Energy and Fuels 2014, 28 (6), 3696-3703.

[2] Wang, L.; Sun, B.; Yang, F. H.; Yang, R. T. Effects of aromatics on desulfurization of liquid fuel by $\pi$-complexation and carbon adsorbents. Chem. Eng. Sci. 2012, 73, 208-217.

[3] Dias da Silva, P.; Samaniego Andrade, S. K.; Zygourakis, K.; Wong, M. S. Adsorptive Desulfurization of Liquid Fuels at Elevated Temperatures Using Metal Exchanged Zeolite Y. Ind. Eng. Chem. Res., 2019, 58, 19623-19632. 